\title{
The effect of price regulation on energy imbalances: A Difference in Differences design is
}

\author{
Stefano Clò ${ }^{\mathrm{a}} *$, Elena Fumagalli ${ }^{\mathrm{b}}$ \\ a Dipartimento di Scienze per l'Economia e l'impresa, University of Florence, Via delle Pandette, 32, 50127 Firenze, Italy \\ ${ }^{\mathrm{b}}$ Copernicus Institute of Sustainable Development, Section Energy and Resources, Utrecht University, Princetonlaan 8a, 3584 CB Utrecht, the Netherlands
}

\section{A R T I C L E I N F O}

\section{Article history:}

Received 4 February 2019

Received in revised form 10 May 2019

Accepted 18 May 2019

Available online 23 May 2019

\section{JEL classifications:}

C01

D21

D22

K32

L51

L94

\section{Keywords:}

Electricity markets

Imbalance pricing

Bidding behavior

Difference-in-Differences

Energy regulation

\begin{abstract}
A B S T R A C T
Providing adequate incentives to schedule energy programs accurately is a critical feature of liberalized electricity markets, particularly those with large shares of intermittent, renewable energy resources. In this regard, two main regulatory approaches are widely adopted in Europe. The single pricing scheme rewards or penalizes market agents according to the impact of their individual imbalances on the system imbalance. The dual pricing scheme penalizes (at best does not reward) all individual energy imbalances. This study theoretically identifies and then provides supporting empirical evidence of potential inconsistencies between market agents' balancing responsibility and the economic incentives provided by these pricing rules (de facto, opportunities for arbitrage in sequential markets). The causal effect of imbalance price regulations on the volume of the energy imbalances is investigated by exploiting a quasi-experimental change in regulation in the Italian power system. A differencein-differences design provides robust evidence that the volume of intentional imbalances significantly decreases when moving from a single to dual pricing scheme. We conclude that the economic incentives of a dual pricing scheme are better aligned with a market agent's responsibility to be balanced and worth of further consideration from a policy perspective.
\end{abstract}

(c) 2019 Elsevier B.V. All rights reserved.

\section{Introduction}

In liberalized electricity markets, the task of maintaining a balance between supply and demand faces new challenges. First, coordination requirements are no longer in the hands of a single, vertically integrated company, but shared between the Transmission System Operator (TSO), managing the transmission network, and market participants. These have the responsibility to ensure that actual (real-time) electricity injections into (and withdrawals from) the network correspond to their energy programs - defined ahead of delivery, normally on the day-ahead market. The duty to balance any residual deviation lays, in turn, with the TSO, who fulfills this task by resorting to flexible generation capacity, traded on the balancing market - the last, in the temporal sequence of markets comprising the wholesale power exchange. Indeed, a second challenge derives from an increasing need for

\footnotetext{
it Acknowledgement We thank Emanuele Bachiocchi and Fabrizio Iacone as well as seminar participants at DEMM (University of Milan) and at the Copernicus Institute of Sustainable Development (Utrecht University), as well as participants at the IAEE conference 2016 in Rome for their helpful comments.

* Corresponding author.

E-mail addresses: stefano.clo@unifi.it (S. Clò), e.m.fumagalli@uu.nl (E. Fumagalli).
}

flexibility, as larger shares of intermittent, renewable generation lower the predictability of supply and demand side programs. While the current energy transition goes in the direction of complying with international agreements on climate change, it is also associated with an increase in the costs directly sustained by TSOs to balance the system, and indirectly experienced by traditional power producers as they are called to operate their plants with higher flexibility (e.g., Perez-Arriaga and Batlle, 2012: Hu et al., 2018). Third, to minimize the residual balancing needs of power markets it is crucial that the institutional arrangements governing balancing responsibilities provide effective incentives for market players to schedule their energy programs accurately, i.e. in line with their expected production or consumption levels. In this regard, European rules require that any deviation from an energy program is settled at a regulated price, reflecting the value of electricity in real-time (EU, 2017). However, the value of energy in real-time normally differs from day-ahead market prices, and these arrangements can provide opportunities for arbitrage across prices in sequential markets. Consequently, program deviations (energy imbalances) might not be minimized, potentially leading to higher balancing costs and, in some cases, to network instabilities (e.g., Scherer et al., 2015). 
The relationship between market agents' balancing responsibility and the economic incentives provided by imbalance pricing rules is a controversial economic issue (e.g., van der Veen et al., 2012). Two main, alternative pricing rules exist: the single pricing scheme and the dual pricing scheme. The former rewards or penalizes market agents according to the impact of their individual program deviation on the system imbalance (the residual deviation). The latter penalizes, at best does not reward, all individual imbalances. Although they have been widely adopted in Europe for quite some time, a comprehensive assessment of the two is still lacking. The objective of this paper is to contribute filling this gap, focusing on the incentive properties of the two pricing schemes in relation to a market agent's responsibility to be balanced. The Italian electricity market provides the empirical setting and a change in regulation, from a single to a dual pricing scheme, creates the ideal environment for a comparative assessment (ARERA, 2016a, 2016c).

The majority of existing work exploring imbalance pricing schemes studies the strategies that a market agent might adopt to exploit arbitrage opportunities in a specific market setting (Boogert and Dupont, 2005; Wawer, 2007; Möller et al., 2011; Scherer et al., 2015; Haring et al., 2015; and Just and Weber, 2015). By simulating a number of these potential strategies against a set of real (or test) market data, these papers unanimously suggest that an agent's programming decision is potentially driven not only by her responsibility to be balanced, but also by the incentives embedded in local (and neighboring) market design. ${ }^{1}$ Only two of the papers in this literature stream specifically focus on assessing comparative advantages and disadvantages of imbalance pricing schemes (Vandezande et al., 2010; van der Veen et al., 2012). Although they adopt rather different methodologies (simple numerical examples and agent-based modelling, respectively) both contributions identify a single pricing scheme as the best choice from an economic efficiency perspective. When the alternatives are compared on the basis of effectiveness, i.e., the accuracy of the energy programs, only van der Veen et al. (2012) recommend the implementation of a dual pricing scheme and only in case of scarcity of flexible resources.

The present work contributes to this literature in several ways. First, we introduce a comprehensive theoretical framework encompassing the two main imbalance pricing rules and derive how they (differently) affect an economic agent's payoff and programming decision. Second, we show that the economic incentives provided by the imbalance pricing rules affect in a statistically significant way the programming decisions taken by market participants. To study the causal effect of price regulation on the volume of energy imbalances, we propose an original empirical strategy, based on a Difference in Differences (DiD) design. In our setting, the actual imbalance volume is benchmarked to the TSO forecasting error. As the latter captures the stochastic component of the imbalance, the difference between the actual imbalance and the forecasting error captures, in turn, the volume of the intentional imbalance (the strategic over- and under-scheduling in the programming stage). In practice, we exploit the quasi-experimental regulatory reform occurred in July 2016 when ARERA, the Italian national Regulatory Authority for Energy, Networks and the Environment, shifted the settlement rules of consumption sites from a single to a dual pricing scheme (ARERA, 2016a, 2016c). In sum, consistently with our theoretical framework, we provide robust evidence that while the actual imbalance was

\footnotetext{
${ }^{1}$ While Boogert and Dupont (2005) find that the potential profit that would results from strategic under/over scheduling in the Dutch market is rarely positive, both Wawer (2007) and Möller et al. (2011) shows that a Balance Responsible Party submitting 'biased schedules' would expect positive payoffs in the German market (both markets applied a single pricing mechanism at the time of the research). Expanding the analysis of potential strategies to include prices on neighboring markets, Scherer et al. (2015) show that the interplay between rules for cross-border trading and national imbalance pricing (a dual pricing scheme) create good profit opportunities for Swiss Balance Responsible Parties willing to act strategically. Differently, Haring et al. (2015) propose an original imbalance settlement scheme (different from those currently used in Europe) which responds to a number of specific objectives. Among other things, the authors are concerned with limiting opportunities for price-related strategies and the subsequent reduction of market liquidity (and increased opportunities to exercise market power).
}

significantly higher than the TSO forecasting error during the single pricing regime, the difference between the two significantly decreased after the implementation of a dual pricing rule. This suggests that the size of the intentional imbalance significantly decreased after the regulatory reform. To the best of our knowledge, this is the first study finding empirical evidence on the differential impact of alternative pricing rules on market agents' imbalance strategies.

Notwithstanding the regulatory preference for single pricing schemes (EU, 2017), the observation that the economic incentives of a dual pricing scheme are better aligned with a market agent's responsibility to be balanced is certainly worth of consideration for multiple reasons: intentional imbalances shift economic transactions from a more liquid and competitive day-ahead market to a highly concentrated and more volatile balancing market; alleged abuses have been contested to market participants profiting, more largely than expected, from imbalance settlements (Scherer et al., 2015; Just and Weber, 2015; ARERA, 2016b); and, more generally, the design of electricity markets is being gradually revised to account not only for larger share of renewable energy resources, but also more active demand.

The remainder of the paper is organized as follows. Section 2 describes the conceptual framework for imbalance settlements, introduces the theoretical model, and formulates two propositions to be tested empirically. The dataset and the empirical strategy are introduced in Section 3. Results and related robustness checks are presented in Section 4 and Section 5, respectively. Section 6 concludes and derives policy implications.

\section{Imbalance drivers: a conceptual framework}

According to European norms, the balancing responsibility of a market participant can be exercised directly or, as more commonly happens, via a Balance Responsible Party (BRP), an ad hoc market entity managing a portfolio of consumption and/or generation sites (EU, 2017). When imbalances occur, the TSO has the duty: i) to balance the market in realtime by procuring flexible resources in a so-called Balancing Market (BM); and ii) to settle, ex-post, the imbalances of the BRPs.

In real-time, a market is short when, on aggregate, the actual level of power generation is lower than the actual level of consumption. In this case, the TSO balances the market by purchasing, on the BM, an extraamount of energy, at the Upward Price $\left(\mathrm{p}^{\mathrm{UP}}\right)$. This is normally higher than the Day-Ahead (DA) market price $\left(\mathrm{p}^{\mathrm{DA}}\right)$, as it reflects not only the increasing marginal cost of production, but also a premium for the flexibility of the generators. Therefore, a market imbalance generates a 'system cost' (for the same extra-amount of energy, end-users would have paid a lower price on the day-ahead). In the opposite, long market case, the actual level of power generation is, on aggregate, higher than the actual level of consumption. To balance the market, the TSO sells back the excess of energy to flexible generators, at the Downward Price $\left(\mathrm{p}^{\mathrm{DN}}\right)$. As this is normally lower than the price paid on the DA, the market imbalance still generates a 'system cost' (end-users are not made whole for the energy not consumed).

BRP's imbalances are settled ex-post via the imbalance fee, product of the BRP's imbalance volume times the imbalance price. For each time unit, the imbalance volume of a BRP responsible, for instance, for a number of consumption sites, is defined as the deviation of the BRP's actual level of consumption from the energy purchased in the programming stage, normally on the DA market. ${ }^{2}$ As such, the BRP's imbalance can be positive or negative. ${ }^{3}$ The imbalance price is designed to reflect the

\footnotetext{
2 The focus of our empirical work is on the behavior of market agents (traders) purchasing electricity on the wholesale market and reselling it to end-users in the retail market, hence the emphasis on BRPs responsible for consumption sites. Notably, the role of the demand in liberalized electricity markets is at the center of the latest package of proposals presented by the European Commission in November 2016 (EU, 2016). Nevertheless, we expect the results of our empirical analysis to hold also for BRPs responsible for nonprogrammable production units.

${ }^{3}$ In the reminder of the paper, a BRP's imbalance is also referred to as the 'individual' imbalance, to distinguish it from the market (or system) imbalance.
} 
real-time value of energy which, in turn, is captured by prices on the Balancing Market (EU, 2017). More specifically, two main alternative imbalance pricing rules - the single pricing scheme and the dual pricing scheme - are applied in European markets today. Here we describe their core features.

\subsection{Single pricing scheme}

According to the single pricing scheme, the imbalance price depends on the sign of the market imbalance (Table 1 ). ${ }^{4}$ A negative sign points to a short market, that is a prevalence of individual, negative imbalances ( $i m b_{i}$, with $i=1 \ldots n$, for $n$ BRPs in the market). In this case, the imbalance price is the maximum between the price on the DA market, $p^{D A}$, and the Upward Price, $p^{U P}$, on the BM. When the sign is positive (long market, caused by a prevalence of individual positive imbalances), the imbalance price is the minimum between the DA price, $p^{D A}$, and the Downward Price, $p^{D N}$, on the BM.

Note that a BRP's individual short position entails the payment of the imbalance fee to the TSO, while the opposite occurs in case of an individual long position. Also, it is important to observe that the following relation holds among prices:

$p^{D N} \leq p^{D A} \leq p^{U P}$

Day-ahead market prices are normally higher than downward prices and normally lower than upward prices. With this in mind, Table 2 shows how the single pricing scheme affects the payoff of the economic agents (the BRPs). This scheme leads to a negative payoff when individual imbalances exhibit the same sign of the market imbalance: agents are penalized because they increase the size of the market imbalance and the related system costs. Conversely, the single pricing scheme rewards economic agents when their individual imbalances are opposite in sign to the market imbalance. Indeed, individual imbalances opposing the market imbalance lower the size of the market imbalance and the related system costs.

In sum, the single pricing scheme can be classified as a marketoriented regulation which, by rewarding or penalizing market agents according to the impact of their imbalances on the system, provides incentives to reduce the system imbalance (profits can be made by helping the system maintain its balance). Also, it is a cost-reflective mechanism which passes through to the individual economic agents the costs or benefits associated to their imbalances. ${ }^{5}$

\subsection{Dual pricing scheme}

According to the dual pricing scheme, an individual long position is settled at a price not higher than the day-ahead price, while an individual short position is settled at a price not lower than the day-ahead price (Table 3). With this, individual imbalances increasing the market imbalance are still penalized (as in the single pricing scheme) while individual imbalances opposing the market imbalance are no longer rewarded, in spite of their positive role in mitigating the size of the market imbalance and the related system costs.

\footnotetext{
${ }^{4}$ That is, for a given sign of the market imbalance, the same price applies to BRPs, irrespectively on whether their imbalance is positive or negative.

5 From the point of view of the TSO, the economic transactions pertaining to imbalance settlements can result in a positive or negative net cash flow. Similarly, also the economic transactions on the BM can result in a positive or negative net cash flow. The algebraic sum of these two net cash flows is socialized via the transmission tariff, paid by end-users. Theoretically, under a single pricing scheme, this algebraic sum equals to zero. Although, this rarely occurs in practice (imbalance pricing schemes are often slightly more complex than described here and TSOs' procurements on the BM are not limited to balancing actions in real-time), the single pricing rule is considered economically efficient from this perspective, i.e. resulting in a zero-sum game for tariff payers (Vandezande et al., 2010).
}

Table 1

Imbalance fee under the single pricing scheme.

\begin{tabular}{lll}
\hline & $\begin{array}{l}\text { Individual long position } \\
\text { or positive imbalance } \\
\left(i m b_{i}>0\right)\end{array}$ & $\begin{array}{l}\text { Individual short position } \\
\text { or negative imbalance } \\
\left(i m b_{i}<0\right)\end{array}$ \\
\hline $\begin{array}{ll}\text { Short market (negative sign) } \\
\text { Long market (positive sign) }\end{array}$ & $\left|i m b_{i}\right| \cdot \max \left(p^{D A} ; p^{U P}\right)$ & $\left|i m b_{i}\right| \cdot \max \left(p^{D A} ; p^{U P}\right)$ \\
\hline
\end{tabular}

Table 2

Payoffs associated to the single pricing scheme.

\begin{tabular}{|c|c|c|}
\hline & $\begin{array}{l}\text { Individual long position } \\
\text { or positive imbalance } \\
\left(i m b_{i}>0\right)\end{array}$ & $\begin{array}{l}\text { Individual short position } \\
\text { or negative imbalance } \\
\left(i m b_{i}<0\right)\end{array}$ \\
\hline Short market (negative sign) & $\left|i m b_{i}\right| \cdot\left(-p^{D A} p^{U P}\right)>0$ & $\left|i m b_{i}\right| \cdot\left(p^{D A}-p^{U P}\right)<0$ \\
\hline Long market (positive sign) & $\left|i m b_{i}\right| \cdot\left(-p^{D A} p^{D N}\right)<0$ & $\left|i m b_{i}\right| \cdot\left(p^{D A}-p^{D N}\right)>0$ \\
\hline
\end{tabular}

Table 3

Imbalance fee under the dual pricing scheme.

\begin{tabular}{|c|c|c|}
\hline & $\begin{array}{l}\text { Individual long position } \\
\text { or positive imbalance } \\
\left(i m b_{\mathrm{i}}>0\right)\end{array}$ & $\begin{array}{l}\text { Individual short position } \\
\text { or negative imbalance } \\
\left(i m b_{i}<0\right)\end{array}$ \\
\hline $\begin{array}{l}\text { Short market (negative sign) } \\
\text { Long market (positive sign) }\end{array}$ & $\begin{array}{c}\left|i m b_{i}\right| \cdot p^{D A} \\
\left|i m b_{i}\right| \cdot \min \left(p^{D A} ; p^{D N}\right)\end{array}$ & $\begin{array}{c}\left|i m b_{i}\right| \cdot \max \left(p^{D A} ; p^{U P}\right) \\
\left|i m b_{i}\right| \cdot p^{D A}\end{array}$ \\
\hline
\end{tabular}

Table 4 illustrates the agents' payoffs associated to the dual pricing scheme. When the individual imbalance shows the same sign of the market imbalance, the dual pricing scheme works exactly as the single pricing scheme and the agents' payoffs are negative. ${ }^{6}$ Conversely, when the individual imbalance shows an opposite sign with respect to the market imbalance, the imbalance price equals the day-ahead price and the related individual payoffs are equal to zero.

In this respect, a dual pricing scheme can be thought as a commandand-control type regulation: individual imbalances are always penalized (at best not rewarded), irrespectively of their impact on the system imbalance and cost. This is the main reason why incentives stemming from the dual pricing scheme are thought to be economically suboptimal compared to those provided by the single pricing scheme.

\subsection{Imbalance drivers under the single and dual pricing schemes}

In this sub-section, we present an extension of the theoretical model by Just and Weber (2015) and study how the two alternative imbalance pricing rules affect the economic agents' programming strategies on the day-ahead (their choice of the bidding quantity). ${ }^{7}$ The model is described from the point of view of market agents purchasing electricity on the wholesale market and reselling it to their own clients in the retail market (i.e., BRPs managing a portfolio of consumption sites).

The quantity of energy, $q_{i}^{D A}$, purchased on the day-ahead, in a given time unit (the hour), by market agent $i$, equals:

$q_{i}^{D A}=q_{i}^{R T L}+i m b_{i}$

where $q_{i}^{R T L}$ is the amount of energy actually consumed by the agent's retail clients. We assume this energy amount to be exogenous, since the bidder strategy on the DA cannot affect its clients' actual level

\footnotetext{
6 The imbalance price is: i) the maximum between the upward balancing price and the day-ahead price in case of a negative imbalance within a short market; and ii) the minimum between the downward balancing price and the day-ahead price in case of a positive imbalance within a long market.

7 Without loss of generality, we intentionally leave out of the economic transactions occurring on the intra-day market.
} 
Table 4

Payoffs associated to the dual pricing scheme.

\begin{tabular}{|c|c|c|}
\hline & $\begin{array}{l}\text { Individual long position } \\
\text { or positive imbalance } \\
\left(\text { imb }_{i}>0\right)\end{array}$ & $\begin{array}{l}\text { Individual short position } \\
\text { or negative imbalance } \\
\left(\mathrm{imb} b_{i}<0\right)\end{array}$ \\
\hline Short market (negative sign) & $\left|i m b_{i}\right| \cdot\left(-p^{D A} p^{D A}\right)=0$ & $\left|i m b_{i}\right| \cdot\left(p^{D A}-p^{U P}\right)<0$ \\
\hline Long market (positive sign) & $\left|i m b_{i}\right| \cdot\left(-p^{D A} p^{D N}\right)<0$ & $\left|i m b_{i}\right| \cdot\left(p^{D A}-p^{D A}\right)=0$ \\
\hline
\end{tabular}

of consumption. The volume of the agent's imbalance can be expressed as:

$i m b_{i}=\sigma_{i}+x_{i}$

For each bidder, the volume of imbalances is the result of a stochastic deviation, $\sigma_{i}$, around the expected level of consumption, $E\left(q_{i}^{R T L}\right)$, and of a strategic decision, $x_{i}$, regarding the energy purchased on the day-ahead. The former is a pure forecasting error originating from the sequential structure of the power exchange. The actual level of consumption can deviate from the amount purchased in the day-ahead market due to exogenous, unpredictable events such as weather conditions, so it is stochastic from the perspective of the bidder. The latter derives from the economic incentives provided by the regulatory framework governing imbalance settlements and enters the objective function of a bidder as a decision variable. Indeed, when submitting a purchase bid, a profit maximizing agent might intentionally decide to purchase an amount of energy which deviates from the expected level of consumption (i.e., $\left.q_{i}^{D A}=E\left(q_{i}^{R T L}\right) \quad x_{i}\right)$. We define such a deviation, $x_{i}$, an intentional imbalance.

The total demand purchased in the day-ahead market $\left(Q^{D A}\right)$ is:

$Q^{D A}=\sum_{i=1}^{n} q_{i}^{D A}=\sum_{i=1}^{n}\left[q_{i}^{R T L}+i m b_{i}\right]$

and it follows the cumulative distribution function $F\left(Q^{D A}\right)$, which we assume to be normal consistently with previous literature (e.g., Hodge et al., 2013). ${ }^{8}$

Each bidder choses the optimal level of intentional imbalances maximizing its expected profits, $E\left(\pi_{i}\right)$. Revenues result from selling electricity, $q_{i}^{R T L}$, in the retail market at the price $p^{R T L}$, which we assume, without loss of generality, to be defined in advance. Costs result from the energy purchased on the day-ahead market, $q_{i}^{D A}$, at the day-ahead price and from settling any eventual imbalance at the imbalance price, $p^{I M B}$, which varies depending on the imbalance settlement rule. Expected profits are expressed as:

$E\left(\pi_{i}\right)=q_{i}^{R T L} p^{R T L}-q_{i}^{D A} E\left(p^{D A}\right)+i m b_{i} E\left(p^{I M B}\right)$

In other words, bidders schedule their purchasing program according to the expected value of, respectively, the day-ahead, $E\left(p^{D A}\right)$, and the imbalance price, $E\left(p^{I M B}\right)$. Both prices are assumed to be exogenous, as the demand-side of the market is competitive and no agent has sufficient market power to unilaterally influence market prices.

We assume risk-neutrality. Bidders are indifferent whether to make an intentional imbalance whenever $E\left(p^{D A}\right)=E\left(p^{I M B}\right)$. Conversely, a potential for arbitrage among prices in sequential markets arises whenever the condition $E\left(p^{D A}\right)=E\left(p^{I M B}\right)$ is no longer valid. In this latter case, bidders evaluate whether to over or under-schedule their purchasing program in the day-ahead market.

\footnotetext{
${ }^{8}$ Assuming that all market agents are capable to forecast the demand of their clients on average correctly, and that the forecast error is normally distributed, the actual demand in the market is normally distributed.
}

We also assume that economic agents formulate their bidding strategies under uncertainty, that is without knowing the direction of the market imbalance. However, they attribute a certain probability of the market being long $F\left(Q^{D A}\right)$ or short $\left(1-F\left(Q^{D A}\right)\right)$.

Under the single pricing scheme, the expected imbalance price equals:

$E\left(p^{I M B}\right)=F\left(Q^{D A}\right) E\left(p^{D N}\right)+\left(1-F\left(Q^{D A}\right)\right) E\left(p^{U P}\right)$

In this case, imbalances are settled at the downward balancing price, $p^{D N}$, when the market is long, while the upward balancing price, $p^{U P}$, applies when the market is short.

After replacing Eqs. (2) and (6) into Eq. (5), we derive the first order conditions of the expected profits, leading to the following optimal level of imbalances:

$i m b_{i}=\frac{1}{\varphi\left(Q^{D A}\right)}\left(\frac{E\left(p^{U P}\right)-E\left(p^{D A}\right)}{E\left(p^{U P}\right)-E\left(p^{D N}\right)}-\Phi\left(Q^{D A}\right)\right)$

With $\varphi(\cdot)$ and $\phi(\cdot)$ being respectively the probability density function (PDF) and the cumulative distribution function (CDF) of the standardized normal distribution.

Eq. (7) provides interesting insights on how the structure of the single pricing scheme affects bidding incentives. Indicating with $y$ the right-hand side of Eq. (7), we observe that a higher probability of the system being long obviously lowers the incentive to over-schedule in the day-ahead $\left(\frac{\partial y}{\partial \Phi\left(Q^{D A}\right)}<0\right)$. Conversely, the incentive to overschedule in the day-ahead increases with both upward and downward prices $\left(\frac{\partial y}{\partial E\left(p^{U P}\right)}>0 ; \frac{\partial y}{\partial E\left(p^{D N}\right)}>0\right)$, while it decreases with the day-ahead price $\left(\frac{\partial y}{\partial E\left(p^{D A}\right)}<0\right)$. Indeed, under a single pricing scheme an increase of the upward balancing price increases both the advantage of a long position (selling the extra energy occurs at a higher price) and the disadvantage of a short position (purchasing the energy shortage becomes costlier). Similarly, a higher downward price lowers both the advantage of a short position (purchasing the energy shortage becomes costlier) and the disadvantage of a long position (selling the extra energy occurs at a higher price). This suggests that an increase in both upward and downward balancing prices creates incentives for over-scheduling in the programming stage. Finally, when the day-ahead price increases, purchasing energy on the day-ahead becomes relatively more expensive, thus decreasing the benefit of a long position.

While the same reasoning applies for the incentives to underschedule in the day-ahead market (taking the opposite sign for all variables), we state our first proposition taking the over-scheduling perspective.

Proposition 1. Under the single pricing scheme, the economic incentives to intentionally over-schedule in the day-ahead market (to take a long position) increase with both the expected downward and upward balancing prices, and decrease with the expected day-ahead price and with the probability of the market imbalance being positive.

Under the dual pricing scheme, the imbalance price varies depending on whether the bidder's imbalance is positive or negative, and it respectively equals:

$\left\{\begin{array}{l}E\left(p^{I M B} \mid i m b_{i}>0\right)=F\left(Q^{D A}\right) E\left(p^{D N}\right)+\left(1-F\left(Q^{D A}\right)\right) E\left(p^{D A}\right) \\ E\left(p^{I M B} \mid i m b_{i}<0\right)=F\left(Q^{D A}\right) E\left(p^{D A}\right)+\left(1-F\left(Q^{D A}\right)\right) E\left(p^{U P}\right)\end{array}\right.$ 
Therefore, expected profits associated to a long and short position can be written as:

$$
\left\{\begin{array}{c}
E\left(\pi_{i} \mid i m b_{i}>0\right)=q_{i}^{R T L}\left(p^{R T L}-E\left(p^{D A}\right)\right)+i m b_{i}\left[F\left(Q^{D A}\right)\left(E\left(p^{D N}\right)-E\left(p^{D A}\right)\right)\right] \\
E\left(\pi_{i} \mid i m b_{i}<0\right)=q_{i}^{R T L}\left(p^{R T L}-E\left(p^{D A}\right)\right)-\left|i m b_{i}\right|\left(1-F\left(Q^{D A}\right)\right)\left(E\left(p^{U P}\right)-E\left(p^{D A}\right)\right)
\end{array}\right.
$$

By comparing the expected profits associated to a long vs. a short position, we first determine the condition under which the former yields higher expected profits than the latter:

$E\left(\pi_{i} \mid i m b_{i}>0\right)>E\left(\pi_{i} \mid i m b_{i}<0\right) \rightarrow \frac{E\left(p^{U P}\right)-E\left(p^{D A}\right)}{E\left(p^{U P}\right)-E\left(p^{D N}\right)}-\phi\left(Q^{D A}\right)>0$

From condition (10), we derive that the incentives to over-schedule in the day-ahead increase with the upward and downward balancing prices, while they decrease with the day-ahead price and with the probability of observing a positive market imbalance. In this regard, the economic incentives stemming from market variables are consistent between the single and the dual pricing scheme.

Next, by maximizing the expected profits associated to a long and short position, we determine the optimal level of imbalances:

$$
\left\{\frac{\partial E\left(\pi_{i} \mid i m b_{i}>0\right)}{\partial x_{i}}=0 \rightarrow i m b_{i}=-\frac{\phi\left(Q^{D A}\right)}{\varphi\left(Q^{D A}\right)} \frac{\partial E\left(\pi_{i} \mid i m b_{i}<0\right)}{\partial x_{i}}=0 \rightarrow i m b_{i}=\frac{1-\phi\left(Q^{D A}\right)}{\varphi\left(Q^{D A}\right)}\right.
$$

By comparing Eqs. (7) and (11), it is immediate to verify that the optimal level of both positive and negative imbalances is always smaller under the dual pricing scheme than under the single pricing scheme. Indeed, the dual pricing scheme either penalizes or does not reward imbalances, thus making it unprofitable to intentionally increase their volume - as illustrated in Eq. (9), under the dual pricing scheme profit maximization implies a minimization of individual imbalances. This brings us to the second proposition to be verified empirically.

Proposition 2. The economic incentives to intentionally over- and underschedule in the day-ahead market (to increase the imbalance volume), are lower under the dual pricing scheme than under the single pricing scheme.

\section{Data and empirical strategy}

In this section, we introduce the data set and the empirical strategy employed to test the validity of the two propositions derived from the theoretical model. The use of data for the Italian Power Exchange (IPEX) represents an ideal choice because of the 2016 regulatory reform. Specifically, on June 16th, 2016 the Italian regulator published a consultation document on its intention to comprehensively redesign the institutional arrangements governing imbalance settlements, also in view of the concomitant, European-wide discussion on the Balancing Guidelines (ARERA, 2016a; EU, 2017). Moreover, on June 24th, 2016 a public procedure was launched, adopting sanctioning measures against a number of BRPs that had showed unusual imbalance positions (ARERA, 2016b). Shortly after that, on August 1st, 2016, the regulator replaced the ten-year old single pricing scheme, which applied to BRPs managing consumption sites (and intermittent, renewable generation resources), with a mixed single-dual pricing scheme (ARERA, 2006; ARERA, 2016c). Within this new regime, imbalance volumes inside a tolerance band (individual imbalances smaller than $\pm 15 \%$ of the scheduled energy withdrawals) remained subject to the single pricing scheme. A dual pricing scheme began to apply, instead, to imbalance volumes outside the tolerance band. In the following, we refer to this modification as the 'regulatory reform'. The first of a series of changes, this reform regarded exclusively the consumption sites, while exempting intermittent, renewable generation resources.

The geographical scope chosen for the empirical strategy is the so-called macro-zone. For imbalance settlement purposes, Italy is divided in two macro-zones: macro-zone North coincides with the energy market zone North while macro-zone South encompasses the rest of the country. In Section 4, we focus the attention on the macrozone South (robustness checks are developed for the macro-zone North in Section 5).

As for the temporal scope of the analysis, the first proposition, concerning bidding incentives under the single pricing scheme, is tested on hourly data from January 1 st, 2015 to July 31th, 2016. The empirical strategy for this pre-reform period is described in Section 3.1. The second proposition, concerning the different volume of imbalances under the two imbalance pricing schemes, is tested by considering data in both the pre- and post-reform periods (January 1st, 2015 May 31th, 2017). The empirical strategy for this analysis is described in Section 3.2.

\subsection{Imbalance drivers under the single pricing scheme}

In studying the economic incentives to over-schedule in the day-ahead market, the main variable of interest is the hourly volume of demand-side imbalances registered in the macro-zone South. Since micro-data on actual consumption are not publicly available, the hourly volume of demand-side imbalances is estimated at macro-zonal level. ${ }^{9}$ Specifically, the macro-zonal, aggregate volume (in $\mathrm{MWh}$ ) of demand-side imbalances observed in hour $t, I M B_{t}$, is computed as the difference between the scheduled energy consumption, $Q_{t}^{S D L}$, and the actual energy consumption, $Q_{t}^{R T L}$, in the same time-geographical scope:

$I M B_{t}=Q_{t}^{S D L}-Q_{t}^{R T L}$

Hourly data on the actual level of consumption, $Q_{t}^{A C T}$, at an aggregate macro-zonal level, are made freely available by the Italian TSO. The hourly amounts of energy purchased in the programming stage are, instead, available at a firm-level and freely downloadable from the IPEX's website. Therefore, scheduled consumption is first estimated at a firm level, $q_{t, i}^{S D L}$, and then aggregated as specified in Eq. (13):

$Q_{t}^{S D L}=\sum_{i=1}^{n} q_{t, i}^{S D L}=\sum_{i=1}^{n} q_{t, i}^{D A}+\sum_{I D=1}^{5} \sum_{i=1}^{n}\left(q_{t, i, b u y}^{I D}-q_{t, i, \text { sell }}^{I D}\right)$

For each firm $i$, with $i=1, \ldots n$, the hourly purchasing bids accepted in the day-ahead market, $q_{t, i}^{D A}$, are adjusted with the related net purchasing position, $q_{t, i, \text { buy }}^{I D}-q_{t, i, \text { sell, }}^{I D}$ in each of the 5 Intra-Day $(I D=1, \ldots . .5)$ market sessions. Firm-level consumption programs are then aggregated at the macro-zonal level.

In the following econometric model, the macro-zonal, aggregate volume of demand-side imbalances (in short, the 'demand-side imbalance') is explained by the relevant market variables identified in the theoretical model:

$I M B_{t}=\alpha+P_{t-24}^{\prime} \beta+\gamma \operatorname{SIGN}_{t-24}+\delta T_{F E}+X^{\prime} \mu+\varepsilon_{t}$

$P$ is a vector of hourly market prices (in $€ / M W h$ ) and includes: $i$ ) the day-ahead national purchasing price, $p^{D A}$, retrieved from the IPEX's website; and ii) the weighted average of the Upward, $p^{U P}$, and

\footnotetext{
9 Two remarks are in order. First, aggregation results in netting individual positive and negative imbalances, and represents a conservative estimation of the individual imbalance volumes. Second, the change in the imbalance price regulation applied only to BRPs responsible for consumption sites. Hence, our main focus is on demand-side imbalances. Nevertheless, among the robustness checks we consider a dependent variable which includes supply-side imbalances from intermittent renewable resources as well.
} 
Downward, $p^{D N}$, prices registered on the balancing market, as computed and made publicly available by the Italian TSO. ${ }^{10}$

$S_{G S N}$ is a binary variable indicating the sign of the macro-zonal imbalance for each hour. A value equal to 1 points to a positive macro-zone imbalance and a value equal to 0 to a negative one. Hourly information on the macro-zonal imbalance sign is made publicly available by the Italian TSO.

Note that for the market prices and the imbalance sign, 24-hour lagged values are adopted as a proxy for market agents' expectations. The underlying idea is that agents build their expectations by observing the market clearing equilibrium in the same hour of the day before.

The Temperature Forecasting Error (in degree Celsius), TFE, is introduced in the model, among the control variables, to capture the stochastic component of the macro-zonal imbalance. This variable is computed as the difference between the actual temperature and the temperature forecasted on the day-ahead for each of the six market zones composing the Italian market. Both actual and forecasted temperatures are estimated hourly at the zonal level, as the average of the temperature in the main cities, weighted by their population.

$X$ is a vector of time fixed effects (year, month, day of the week and hour, hereby YMDH) to control for potential trends and seasonality within the year. An additional dummy variable was introduced to identify hours which experience peaks in electricity demand (for example, hours that were exceptionally hot or cold). ${ }^{11}$

Before proceeding with the empirical analysis, we performed the Augmented Dickey-Fuller (ADF) test and the Phillips-Perron (PP) test (Dickey and Fuller, 1979; Phillips and Perron, 1988) to check for the presence of a unit root in the main variables (Table 5). The number of lags in each test was chosen using the Akaike's information criterion and the Schwarz's Bayesian information criterion (Akaike, 1974; Schwarz, 1978). Results of the two tests always pointed to the same direction and do not reject the null hypothesis of a unit root. Hence, we take the series to be non-stationary. To address this problem, we adopt the variance estimator of Newey-West (1987) which allows obtaining Heteroskedasticity and Autocorrelation Consistent Standard Errors.

\subsection{Impact of the regulatory change on imbalance volumes: a DiD design}

To study whether imbalance pricing schemes differentially affect the bidding decisions of market agents, we design a DiD quasi-experiment. Specifically, we test whether the demand-side imbalance is affected by a change in the imbalance price regulation, while controlling for the TSO's load forecasting error (TSOFE).

The intuition behind this choice is the following. Energy imbalances include an intentional and a stochastic component. In line with the theoretical model, we expect the former to be affected by the imbalance pricing rule and to be larger in volume under a single than a dual pricing scheme. The latter derives, instead, from errors in forecasting actual consumption, also due to exogenous, unpredictable events such as weather conditions.

We claim that the stochastic component of the demand-side imbalance can be suitably captured by the forecasting error made by the TSO $\left(\mathrm{TSOFE}_{t}\right)$ in estimating the electricity consumption for each hour of the following day. ${ }^{12}$ As the TSO forecasts the hourly energy consumption

\footnotetext{
10 The Italian regulation uses average balancing prices because the pricing rule on the Italian BM is pay-as-bid. Accepted quantities for each price level are used as weights.

${ }^{11}$ We consider an hour to be an outlier when the demand is $>3.6$ times the residuals' standard deviation, in absolute value - a rule of thumb similar to the one used in Juselius (2006). The inclusion of this dummy variable does not affect our results.

12 We construct this variable as the difference between the TSO electricity consumption forecast and the corresponding level of actual electricity consumption, both data being available from the TSO's website. The forecasted consumption is estimated by the TSO using consolidated algorithms which account for historical data, expected weather conditions and network losses. Socio-economic events capable to influence the demand for electricity and known in advance, such as city holidays, strikes of particular production categories, television programs of particular interest are also considered (Terna, 2005).
}

Table 5

Unit root tests.

\begin{tabular}{lrr}
\hline Variable & ADF in levels & PPERRON in levels \\
\hline Macro-zone South & & \\
$I M B_{z}$ - Demand-side imbalance $(\mathrm{MWh})$ & $-24.2^{* * *}$ & $-27.2^{* * *}$ \\
$p^{D A}$ - Day-Ahead price $(€ / \mathrm{MWh})$ & $-22.4^{* * *}$ & $-27.1^{* * *}$ \\
$p^{U P}$ - Upward price $(€ / \mathrm{MWh})$ & $-57.7^{* * *}$ & $-76.8^{* * *}$ \\
$p^{D N}$ - Downward price $(€ / \mathrm{MWh})$ & $-46.43^{* * *}$ & $-72.4^{* * *}$ \\
$T F E$ - Temperature forecasting error $\left({ }^{\circ} \mathrm{C}\right)$ & $-32.3^{* * *}$ & $-31.2^{* * *}$ \\
\hline$* * * \quad p<0.01$. & &
\end{tabular}

to optimize grid operations, such control variable is unaffected by the imbalance price regulation (the treatment) but is otherwise driven by the same, exogenous factors which influence the stochastic component of the demand-side imbalance.

In the empirical application, the stochastic component of the demand-side imbalance (treated group) is captured by the pre and post-treatment trend of the TSOFE (control group). In turn, this permits to isolate the intentional component of the demand-side imbalance and to assess how its volume is affected by the regulatory change.

We first compare the evolution of the demand-side imbalance in the macro-zone South with the TSO's load forecasting error, before and after the regulatory reform. The trends of the demand-side imbalance and of the TSO forecasting error are compared using hourly data for the entire observation period (01/01/2015-31/05/2017) in Fig. 1, and for a narrower period (01/04/2016-30/09/2016) in Fig. 2, where daily average data are employed. ${ }^{13}$ Similarly, the descriptive statistics, reported in Table 6 for all variables, are provided separately for the pre- and post-reform periods.

Figs. 1 and 2 provide graphical evidence of a reduction in the demand-side imbalance volume and its convergence towards the level of the TSO's load forecasting error, after the regulatory reform. The descriptive statistics reported in Table 6 suggest that the reduction of the difference between the two variables, i.e., of the size of the intentional imbalances, observed in the post-reform period is not driven by any significant change in the identified, potential imbalance drivers. Moreover, this trend is consistent with Proposition 2: after the regulatory reform was implemented, the demand-side imbalance converges towards the TSO's load forecasting error and show similar volumes and trend.

In sum, we suggest that the DiD estimator is unbiased if the treatedcontrol difference is relevant only in the pre-treatment period, and not in the post-treatment period. The model employed to test it is specified in the following way:

$$
\begin{aligned}
\mathrm{DV}_{t}= & \alpha+\beta \text { TREATED }_{t}+\gamma R E G_{-} \text {CHANGE }_{t}+\delta \text { DIFF }_{t}+\rho \text { TFE }_{t}+P_{t-24}^{\prime} \sigma \\
& +\tau \text { SIGN }_{t-24}+X^{\prime} \mu+\varepsilon_{t}
\end{aligned}
$$

TREATED is a dichotomy variable taking the value 1 when the observation refers to the treated group and 0 when it refers to the control group. In the former case the dependent variable $\left(D V_{t}\right)$ corresponds to the demand-side imbalance, $I M B_{t}$, while in the latter case it corresponds to the TSO's load forecasting error, TSOFE . $_{\text {. }}$

REG_CHANGE is another binary variable equaling 1 after the regulatory reform and zero otherwise.

The variable DIFF is obtained from the interaction of the TREATED and REG_CHANGE binary variables. It captures the impact of the change in regulation on the treated group.

The model also includes the expected drivers of the imbalance - the temperature forecasting error, TFE, the vector $P$ of expected market

\footnotetext{
13 While the regulatory reform effectively entered into force on August 1st, 2016, the date of June 16th, 2016 is highlighted Figs. 1 and 2. This is when the consultation document was published.
} 


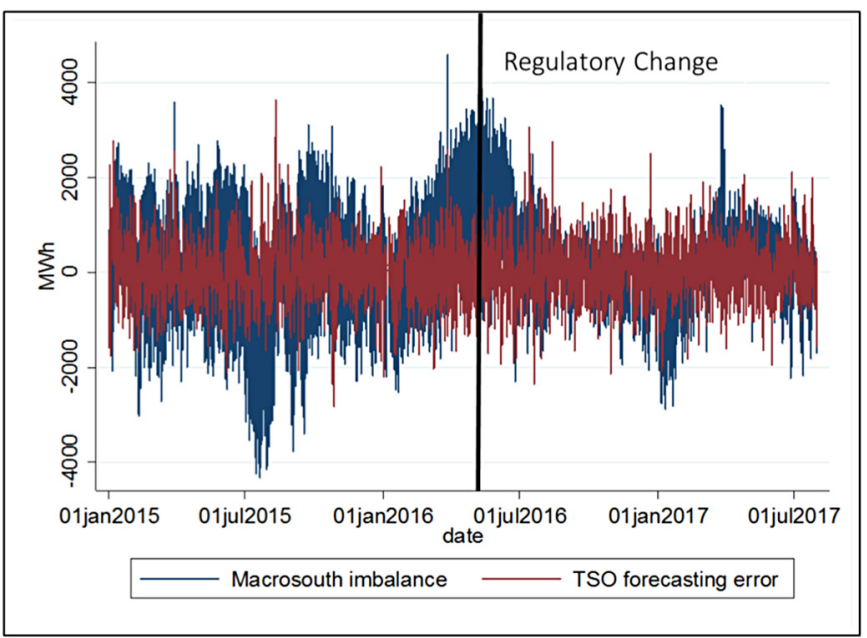

Fig. 1. Demand-side imbalance and TSO's load forecasting error before and after the publication of the consultation document on the regulatory reform - Hourly data (01/ 01/2015-31/05/2017) - Macro-zone South.

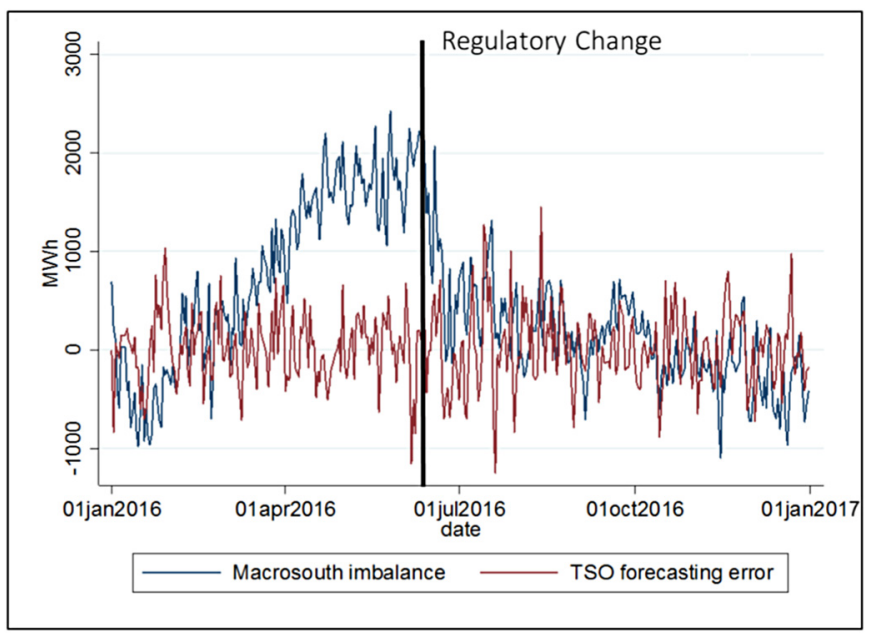

Fig. 2. Demand-side imbalances and TSO's load forecasting error before and after the publication of the consultation document on the regulatory reform - Daily average data (01/01/2016-31/12/2016) - Macro-zone South.

prices, and the expected sign of the macro-zonal imbalance, SIGN - as well as a vector $X$ of time fixed effects.

We first run a pooled regression where the Newey-West estimator is adopted to ensure heteroskedastic and auto-correlation consistent estimators. We next run a panel regression with fixed effects to control for unobserved heterogeneity or for factors which change over time but not across groups.

\section{Empirical results}

This section reports the results of our empirical investigation. We first analyze the drivers of the demand-side imbalance under the single pricing scheme, by estimating the model presented in Section 3.1.

Estimates of Eq. (14) are reported in Table 7. The estimated coefficients are highly significant and their signs confirm the prediction of our theoretical model. Consistent with Proposition 1, the volume of positive, demand-side imbalances increases when both the upward and downward balancing prices are expected to increase, while it decreases with an expected increase in day-ahead prices and with the expectation of observing a positive macro-zonal imbalance sign. These results fully support our intuition that the economic incentives provided by the imbalance pricing scheme are significant for the programming decisions. This suggests that market agents adapt their bidding strategies on the day-ahead to take into account, not only their expected energy needs, but also the potential arbitrage opportunities stemming from price differentials in subsequent markets. Notably, it is rational for economic agents to over-schedule in the day-ahead market when increasing upward (downward) prices and decreasing day-ahead market prices are expected. Within a short market, higher upward prices amplify both the advantage of an individual long position and the disadvantage of an individual short position (the agent respectively anticipates to sell back the extra energy at a higher price and to purchase the energy shortage at a higher price). Similarly, within a long market, higher downward prices reduce both the disadvantage of an individual long position and the advantage of an individual short position (the agent respectively anticipates to sell back the extra energy at a higher price and to purchase the energy shortage at a higher price).

Secondly, we empirically test our DiD design, by estimating the model presented in Section 3.2. First, a pooled OLS with Newey-West SE is implemented. Column (1) of Table 8 presents the main results without control variables, while all other specifications include progressively the full set of control variables. All estimates of our variable of interest are statistically significant and confirm that the regulatory reform affected the demand-side imbalance. The difference between the demand-side imbalance and the TSO's load forecasting error in the macro-zone South was significantly higher under a single pricing scheme than under a mixed single-dual pricing scheme. This suggests that the discrepancy between an agent's balancing responsibility and the economic incentives provided by the imbalance pricing rule is significantly mitigated by the dual pricing scheme.

In particular, the empirical analysis shows that the coefficient of the variable TREATED, i.e., the pre-treatment intercept of the treated group, is positive and statistically significant (statistically different from the intercept of the control group). This indicates a positive and significant divergence of the demand-side imbalance from the TSO's load forecasting error in the pre-reform period.

The coefficient of the variable DIFF, i.e. the post-treatment intercept of the treated group, measures to what extent the demand-side imbalance varied after the treatment and measures the related impact of the regulatory change. This coefficient is negative and statistically significant, indicating that the regulatory reform induced a reduction of the volume of the demand-side imbalance which, in the post-treatment period shares a common trend with the TSO's load forecasting error.

These results are confirmed also after the inclusion in the model of the other control variables, whose coefficients are consistent with the results presented in Table 7.

In Table 9, we show that the main results are confirmed when the coefficients are estimated using a panel model with fixed effects. The coefficient of the TREATED variable is omitted as this variable does not vary over time, while the coefficient of the DIFF variable is again negative and statistically significant, suggesting that the volume of the demand-side imbalance decreased after the regulatory change.

\section{Robustness checks}

In this section, we present a variety of robustness checks to exclude the possibility of our main results being dependent on the chosen empirical strategy. Specifically, we show that results are robust to alternative specifications of the explanatory variables, of the dependent variable and of the chosen estimator. Robustness checks have been run with respect to both empirical analyses.

Hereby, we focus on the first empirical model (presented in Section 3.1) where we investigate the determinants of the demandside imbalances under the single pricing scheme. A first potential criticism regards the choice to use a 24-hour lag as a proxy of the prices and imbalance sign's expectations. To exclude the possibility that our results depend on this choice, or on the model linearity, we run again 
Table 6

Descriptive statistics for the macro-zone South.

(Source: own elaboration on GME's and Terna's data.)

\begin{tabular}{|c|c|c|c|c|c|}
\hline & N. obs & Mean & Std. Dev. & Min & Max \\
\hline \multicolumn{6}{|l|}{ Pre-reform (01/01/2015-31/07/2016) } \\
\hline IMB - Demand-side imbalance (MWh) & 13,870 & 285.01 & 1262.50 & -4824.30 & 4585.16 \\
\hline TSOFE - TSO's load forecasting error (MWh) & 13,870 & 19.38 & 556.66 & -5855.00 & 3637.00 \\
\hline SIGN -Imbalance sign (binary) & 13,870 & 0.54 & 0.50 & 0.00 & 1.00 \\
\hline$p^{D A}$ - Day-Ahead price $(€ / \mathrm{MWh})$ & 13,870 & 47.00 & 14.00 & 5.62 & 144.57 \\
\hline$p^{U P}$ - Upward price $(€ / \mathrm{MWh})$ & 13,870 & 108.26 & 70.44 & 0.00 & 792.27 \\
\hline$p^{D N}$ - Downward price $(€ / \mathrm{MWh})$ & 13,870 & 11.86 & 10.53 & 0.00 & 96.92 \\
\hline \multicolumn{6}{|c|}{ TFE - Temperature forecasting error $\left({ }^{\circ} \mathrm{C}\right)$ by market zone } \\
\hline South & 13,870 & 0.05 & 0.38 & -2.50 & 3.60 \\
\hline Centre-South & 13,870 & -0.02 & 0.49 & -3.20 & 3.90 \\
\hline Centre-North & 13,870 & -0.04 & 0.47 & -3.10 & 2.60 \\
\hline Sardinia & 13,870 & -0.03 & 0.41 & -2.50 & 2.20 \\
\hline Sicily & 13,870 & -0.09 & 0.38 & -2.10 & 2.20 \\
\hline \multicolumn{6}{|l|}{ Post-reform (01/08/2016-31/05/2017) } \\
\hline IMB - Demand-side imbalance (MWh) & 8015 & 25.73 & 676.19 & -9381.53 & 3521.93 \\
\hline TSOFE - TSO's load forecasting error (MWh) & 8015 & 37.06 & 503.47 & -9520.00 & 2751.00 \\
\hline SIGN -Imbalance sign (binary) & 8015 & 0.48 & 0.50 & 0.00 & 1.00 \\
\hline$p^{D A}$ - Day-Ahead price $(€ / \mathrm{MWh})$ & 8015 & 50.42 & 15.02 & 10.00 & 162.41 \\
\hline$p^{U P}$ - Upward price $(€ / \mathrm{MWh})$ & 8015 & 101.56 & 93.43 & 0.00 & 801.70 \\
\hline$p^{D N}$ - Downward price $(€ / \mathrm{MWh})$ & 8015 & 17.31 & 12.20 & 0.00 & 214.28 \\
\hline \multicolumn{6}{|c|}{ TFE - Temperature forecasting error $\left({ }^{\circ} \mathrm{C}\right)$ by market zone } \\
\hline South & 8015 & -0.07 & 0.95 & -17.35 & 8.05 \\
\hline Centre-South & 8015 & 0.08 & 0.91 & -18.85 & 5.15 \\
\hline Centre-North & 8015 & -0.10 & 1.24 & -22.05 & 5.25 \\
\hline Sardinia & 8015 & 0.43 & 1.79 & -14.95 & 10.55 \\
\hline Sicily & 8015 & -0.18 & 1.05 & -16.25 & 7.25 \\
\hline
\end{tabular}

the regressions using a different specification of the explanatory variables. Results reported in Table 10 show that our main findings are confirmed when using: i) the moving average of the main explanatory variables (Column 1); ii) a log specification of the explanatory variables to account for non-linearity (Column 2); iii) the real-time value of the explanatory variables (Column 3 ).

A second potential critique of the proposed econometric analysis might concern the choice of the dependent variable. We have chosen to focus the analysis on the demand-side imbalance because the regulatory reform concerned only the consumption sites. Moreover, we decided to focus on the macro-zone South. Results reported in Table 11 show that our main findings are confirmed: i) when the imbalances of the intermittent renewable generation sites (wind and solar photovoltaic plants, also subject to a single pricing scheme) are added to the demand-side imbalance (Column 1); ii) when the analysis of the demand-side imbalance is carried out on the macro-zone North (Column 2); iii) when demand-side and renewable imbalances are jointly considered for the macro-zone North (Column 3).

Table 7

Drivers of the demand-side imbalance - Newey-West HAC SE.

\begin{tabular}{lccc}
\hline & $(1)$ & $(2)$ & $(3)$ \\
\hline$p^{D A}(24$ h lag $)$ & $-14.641^{* * *}$ & $-19.215^{* * * *}$ & $-19.117^{* * *}$ \\
& $(2.210)$ & $(2.296)$ & $(2.312)$ \\
$p^{U P}(24$ h lag $)$ & & $1.565^{* * *}$ & $1.539^{* * *}$ \\
& & $(0.184)$ & $(0.181)$ \\
$p^{D N}$ (24 h lag) & & $12.873^{* * *}$ & $10.607^{* * *}$ \\
& & $(1.840)$ & $(1.829)$ \\
SIGN (24 h lag) & & $-197.450^{* * *}$ \\
& & & $(30.731)$ \\
Constant & $1381.300^{* * *}$ & $1222.163^{* * *}$ & $1319.589^{* * *}$ \\
& $(195.946)$ & $(188.430)$ & $(184.659)$ \\
Observations & 13,846 & 13,846 & 13,846 \\
R-squared & 0.566 & 0.581 & 0.587 \\
YMDH TFE & Yes & Yes & Yes \\
\hline
\end{tabular}

Standard errors in parentheses. ${ }^{* *} p<0.05,{ }^{*} p<0.1$.

*** $p<0.01$.
Finally, we have adopted the Newey-West estimator to address the problem of heteroskedasticity and serial correlation. We want to verify that our estimates do not depend on this choice. Hence, we take an alternative approach to address the problem of serial correlation in residuals. We perform a multivariate linear regression where the lags of the dependent variable are added among the explanatory variables. The number of lags is chosen according to the results of different residual autocorrelation tests. In other words, we add lags of the dependent variable as far as the Ljung-Box Portmanteau (Q) test for white noise, the Bartlett's periodogram-based test for white noise and the BreuschGodfrey serial correlation test simultaneously reject the null hypothesis of serial correlation of the residues. Also this specification of the model largely confirms our main results (Table 12).

Table 8

Impact of the regulatory reform on the demand-side imbalance in the Italian macro-zone South - Pooled OLS with Newey-West HAC SE.

\begin{tabular}{lcccc}
\hline & $(1)$ & $(2)$ & $(3)$ & $(4)$ \\
\hline TREATED & $268.740^{* * *}$ & $269.085^{* * *}$ & $268.988^{* * *}$ & $269.038^{* * *}$ \\
& $(35.182)$ & $(34.827)$ & $(34.609)$ & $(34.584)$ \\
REG_CHANGE & $-310.007 * * *$ & $-227.540^{* * *}$ & $-227.172^{* * *}$ & $-230.050^{* * *}$ \\
& $(58.538)$ & $(61.998)$ & $(61.545)$ & $(61.583)$ \\
DIFF & $-284.553^{* * *}$ & $-283.893^{* * *}$ & $-283.758^{* * *}$ & $-283.680^{* * *}$ \\
& $(48.134)$ & $(47.470)$ & $(47.226)$ & $(47.219)$ \\
$p^{\text {DA }}$ (24 h lag) & & $-7.099^{* * *}$ & $-8.684^{* * *}$ & $-8.595^{* * *}$ \\
& & $(1.508)$ & $(1.543)$ & $(1.546)$ \\
$p^{\text {UP }}$ (24 h lag) & & & $0.364^{* * *}$ & $0.353^{* * *}$ \\
& & & $(0.095)$ & $(0.096)$ \\
$p^{D N}$ (24 h lag) & & & $5.601 * * *$ & $5.156^{* * *}$ \\
& & & $(0.937)$ & $(0.931)$ \\
SIGN (24 h lag) & & & & $-46.585^{* * *}$ \\
& & & & $(16.634)$ \\
Constant & -49.505 & 957.657 & $927.955^{* * *}$ & $949.411^{* * *}$ \\
& $(68.930)$ & $(0.000)$ & $(125.629)$ & $(125.940)$ \\
Observations & 42,036 & 41,988 & 41,988 & 41,988 \\
YMDH TFE & Yes & Yes & Yes & Yes \\
\hline
\end{tabular}

Standard errors in parentheses. ${ }^{* *} p<0.05,{ }^{*} p<0.1$

*** $p<0.01$. 
Table 9

Impact of the regulatory change on the demand-side imbalance in the Italian macro-zone South - Panel regression with fixed effects and robust SE.

\begin{tabular}{lcccc}
\hline & $(1)$ & $(2)$ & $(3)$ & $(4)$ \\
\hline TREATED & - & - & - & - \\
REG_CHANGE & -311.041 & -228.069 & -228.763 & -232.083 \\
& $(267.242)$ & $(170.400)$ & $(165.895)$ & $(173.855)$ \\
DIFF & $-284.553^{* * *}$ & $-284.251^{* * *}$ & $-284.251^{* * *}$ & $-284.251^{* * *}$ \\
& $(0.000)$ & $(0.000)$ & $(0.000)$ & $(0.000)$ \\
$p^{D A}$ (24 h lag) & & -7.063 & -8.670 & -8.520 \\
& & $(8.436)$ & $(9.496)$ & $(9.138)$ \\
$p^{\text {UP }}$ (24 h lag) & & & 0.335 & 0.322 \\
& & & $(0.412)$ & $(0.380)$ \\
$p^{\text {DN }}$ (24 h lag) & & & 5.729 & 5.348 \\
& & & $(3.802)$ & $(2.888)$ \\
SIGN (24 h lag) & & & -41.192 \\
& & & & $(98.720)$ \\
Constant & 269.179 & 682.298 & 640.096 & 660.359 \\
& $(105.188)$ & $(382.700)$ & $(333.704)$ & $(382.269)$ \\
Observations & 42,036 & 41,988 & 41,988 & 41,988 \\
YMDH TFE & Yes & Yes & Yes & Yes \\
\hline
\end{tabular}

Standard errors in parentheses. ${ }^{* *} p<0.05,{ }^{*} p<0.1$.

$* * * \quad p<0.01$.

As for the second empirical model (presented in Section 3.2), additional analyses have been developed to test the robustness of our results to alternative specifications of the DiD design. Specifically, we find our main results to be confirmed under a different specification of the control variables and of the dependent variable. In the former case, the main results of the $\mathrm{DiD}$ regression are confirmed when the moving average (Column 1), the logarithmic form (Column 2) and the real value of the control (market prices and sign) variables (Column 3 ) are used instead of their $24 \mathrm{~h}$ lagged values (Table 13). In the latter case, we find that our main results are valid when we analyze the demand imbalances registered both in the South and in the North macro-zones. As reported in Table 14, this holds under both a pooled OLS with Newey-West SE (Column 1) and a panel regression with fixed effects (Column 2).

Finally, we show that our results are robust to an alternative specification of the estimator. We adopt a GLS approach to correct for heteroscedasticity and auto-correlation in the standard errors. Indeed, the diagnostic Wooldridge test for autocorrelation in panel data rejects the null hypothesis, pointing to the presence of serial correlation, and the result of the Wald test also rejects the null hypothesis and concludes for the presence of heteroscedasticity (Table 15). In light of these

\section{Table 10}

Drivers of the demand-side imbalance - Newey-West HAC SE with alternative specifications of the explanatory variables.

\begin{tabular}{lccc}
\hline & $(1)$ & $(2)$ & $(3)$ \\
\hline$p^{D A}$ & $-40.927 * * *$ & $-846.247 * * *$ & $-18.673 * * *$ \\
& $(4.425)$ & $(128.643)$ & $(2.267)$ \\
$p^{U P}$ & $4.901^{* * *}$ & 4.751 & $1.346^{* * *}$ \\
& $(0.686)$ & $(9.358)$ & $(0.181)$ \\
$p^{D N}$ & $18.241^{* * *}$ & $136.337 * * *$ & $9.399 * * *$ \\
& $(5.932)$ & $(22.307)$ & $(1.759)$ \\
SIGN & -30.635 & $-305.739 * * *$ & $-238.965 * * *$ \\
& $(94.431)$ & $(44.943)$ & $(30.406)$ \\
Constant & $2312.131^{* * *}$ & $3690.650^{* * *}$ & $1482.429 * * *$ \\
& $(276.251)$ & $(522.734)$ & $(189.988)$ \\
Observations & 13,869 & 13,846 & 13,846 \\
YMDH TFE & Yes & Yes & Yes \\
Moving average of explanatory & $\mathrm{x}$ & & $\mathrm{x}$ \\
$\quad$ variables & & & \\
Log form of explanatory variables & & & \\
Real-time explanatory variables & & & \\
\hline
\end{tabular}

Standard errors in parentheses. ${ }^{* *} p<0.05,{ }^{*} p<0.1$.

$* * * \quad p<0.01$.
Table 11

Drivers of the demand-side imbalance - Newey-West HAC SE with alternative specifications of the dependent variable.

\begin{tabular}{lccc}
\hline & $(1)$ & $(2)$ & $(3)$ \\
\hline$p^{D A}(24 \mathrm{~h}$ lag $)$ & $-6.241^{*}$ & $-8.077^{* * *}$ & 2.954 \\
& $(3.185)$ & $(1.969)$ & $(2.611)$ \\
$p^{U P}(24 \mathrm{~h}$ lag $)$ & $2.010^{* * *}$ & -0.068 & 0.031 \\
& $(0.279)$ & $(0.175)$ & $(0.207)$ \\
$p^{D N}(24 \mathrm{~h}$ lag $)$ & $13.510^{* * *}$ & $13.364^{* * *}$ & $16.662^{* * *}$ \\
& $(2.683)$ & $(1.803)$ & $(2.036)$ \\
SIGN (24 h lag) & $-295.055^{* * *}$ & $-319.448^{* * *}$ & $-347.861^{* * *}$ \\
& $(43.501)$ & $(34.211)$ & $(39.479)$ \\
Constant & $922.011^{* * *}$ & $-293.054^{*}$ & $-1508.788^{* * *}$ \\
& $(240.536)$ & $(162.387)$ & $(199.205)$ \\
Observations & 13,846 & 13,846 & 13,846 \\
Demand RES imbalances & $\mathrm{x}$ & & \\
in the South macrozone & & & \\
Demand imbalances in the & & & \\
North macrozone & & & Yes \\
Demand RES imbalances & & & \\
in the North macrozone & Yes & & \\
YMDH TFE & & & \\
\hline
\end{tabular}

Standard errors in parentheses. ${ }^{* *} p<0.05,{ }^{*} p<0.1$.

*** $p<0.01$.

$* p<0.1$.

results, we use feasible generalized least squares which allows for robust estimations in the presence of AR(1) autocorrelation within panels and heteroskedasticity across panels. Again, results presented in Table 16 widely confirm our findings.

\section{Conclusions}

In light of the current energy transition, the institutional settings governing imbalance settlements have a prominent role in fostering market agents' responsibility in balancing power markets. Nevertheless, the two dominant imbalance pricing rules currently adopted in European markets provide rather different economic incentives in this regard. By penalizing any deviation from energy programs, a dual pricing scheme induces BRPs to minimize their individual imbalances. Differently, by rewarding deviations that reduce the market imbalance, a single pricing scheme creates more opportunities for BRPs to profitably over- and under-schedule ahead of the time of delivery, conditionally on their capacity to help the system to be balanced.

The idea that a profit maximizing BRP coherently responds to such economic incentives and exploits arbitrage opportunities on sequential markets, emerges clearly from the theoretical model. Using an original empirical approach, in combination with Italian market data, this

Table 12

Drivers of the demand-side imbalance - OLS with lagged dependent variable.

\begin{tabular}{lccc}
\hline & $(1)$ & $(2)$ & $(3)$ \\
\hline$p^{D A}$ (24 h lag) & -0.260 & $-0.784^{* *}$ & $-0.817^{* *}$ \\
& $(0.376)$ & $(0.391)$ & $(0.387)$ \\
$p^{U P}$ (24 h lag) & & $0.164^{* * *}$ & $0.159^{* * *}$ \\
& & $(0.045)$ & $(0.045)$ \\
$p^{D N}$ (24 h lag) & & $1.353^{* * *}$ & 0.352 \\
& & $(0.318)$ & $(0.321)$ \\
SIGN (24 h lag) & & $-91.303^{* * *}$ \\
& & & $(6.642)$ \\
Constant & 5.407 & -4.304 & 41.723 \\
& $(33.004)$ & $(33.155)$ & $(32.968)$ \\
Observations & 13,798 & 13,798 & 13,798 \\
YMDH TFE & Yes & Yes & Yes \\
DepVar Number of lags & 72 & 72 & 72 \\
\hline
\end{tabular}

Standard errors in parentheses. ${ }^{*} p<0.1$.

$* * * \quad p<0.01$.

$* * \quad p<0.05$. 
Table 13

DiD - Pooled OLS with Newey-West HAC SE and alternative specifications of the control variables.

\begin{tabular}{|c|c|c|c|}
\hline & (1) & $(2)$ & (3) \\
\hline TREATED & $\begin{array}{l}269.655^{* * * *} \\
(34.191)\end{array}$ & $\begin{array}{l}270.650 * * * \\
(34.768)\end{array}$ & $\begin{array}{c}268.501^{* * * *} \\
(34.506)\end{array}$ \\
\hline REG_CHANGE & $\begin{array}{c}-160.844 * * \\
(65.055)\end{array}$ & $\begin{array}{c}-261.439 * * * \\
(63.457)\end{array}$ & $\begin{array}{c}-218.078 * * * \\
(61.467)\end{array}$ \\
\hline DIFF & $\begin{array}{c}-283.868 * * * \\
(47.253)\end{array}$ & $\begin{array}{c}-282.732 * * * \\
(47.568)\end{array}$ & $\begin{array}{c}-284.131^{* * * *} \\
(47.105)\end{array}$ \\
\hline$p^{D A}$ & $\begin{array}{c}-14.567 * * * \\
(2.367)\end{array}$ & $\begin{array}{c}-294.928 * * * \\
(74.693)\end{array}$ & $\begin{array}{c}-9.138 * * * \\
(1.552)\end{array}$ \\
\hline$p^{U P}$ & $\begin{array}{c}1.310^{* * *} \\
(0.413)\end{array}$ & $\begin{array}{c}-8.410 * * \\
(3.873)\end{array}$ & $\begin{array}{c}0.314^{* * *} \\
(0.095)\end{array}$ \\
\hline$p^{D N}$ & $\begin{array}{l}9.495^{* * *} \\
(2.718)\end{array}$ & $\begin{array}{l}55.012 * * * \\
(10.207)\end{array}$ & $\begin{array}{c}3.975 * * * \\
(0.943)\end{array}$ \\
\hline SIGN & $\begin{array}{c}-86.475^{*} \\
(47.858)\end{array}$ & $\begin{array}{c}-84.516^{* * *} \\
(24.403)\end{array}$ & $\begin{array}{c}-66.508^{* * *} \\
(16.466)\end{array}$ \\
\hline Constant & $\begin{array}{c}1129.125 * * * \\
(156.982)\end{array}$ & $\begin{array}{c}1296.006 * * * \\
(331.041)\end{array}$ & $\begin{array}{l}981.524 \\
(0.000)\end{array}$ \\
\hline $\begin{array}{l}\text { Observations } \\
\text { vce }\end{array}$ & $\begin{array}{l}41,982 \\
\text { robust }\end{array}$ & $\begin{array}{l}41,988 \\
\text { robust }\end{array}$ & $\begin{array}{l}41,988 \\
\text { robust }\end{array}$ \\
\hline YMDH TFE & YES & YES & YES \\
\hline $\begin{array}{l}\text { Moving average of explanatory } \\
\text { variables* }\end{array}$ & $\mathrm{x}$ & & \\
\hline Log form of explanatory variables* & & $\mathrm{x}$ & \\
\hline Real-time explanatory variables* & & & $\mathrm{X}$ \\
\hline
\end{tabular}

Standard errors in parentheses.

$* * * \quad p<0.01$.

$* * p<0.05$.

$* p<0.1$.

study finds robust evidence of such expected behavior and confirms that the incentives provided under a dual pricing scheme are better aligned with the normative responsibility of a BRP.

Indeed, an institutional arrangement where the normative framework establishes a responsibility 'to be balanced', while the economic incentives foster the creation of intentional imbalances (although in principle, in the direction of helping the system to be in balance) can lead to unnecessary system costs, and expose power systems to extreme behavior and instability particularly when loopholes are found in the local market design. Nevertheless, the opportunity to benefit from a programming decision that supports the system's stability is particularly relevant for those markets agents (consumers

Table 14

DiD - Pooled OLS with Newey-West HAC SE and Panel regression with fixed effect and alternative specifications of the dependent variable: South North.

\begin{tabular}{|c|c|c|}
\hline & (1) & $(2)$ \\
\hline TREATED & $\begin{array}{c}192.220 * * * * \\
(10.163)\end{array}$ & - \\
\hline REG_CHANGE & $\begin{array}{c}-75.884^{* * * *} \\
(14.268)\end{array}$ & $\begin{array}{c}-55.738^{* * * *} \\
(13.889)\end{array}$ \\
\hline DIFF & $\begin{array}{c}-57.001 * * * \\
(11.973)\end{array}$ & $\begin{array}{c}-57.001 * * * \\
(11.842)\end{array}$ \\
\hline$p^{D A}$ (24 h lag) & $\begin{array}{c}-5.054 * * * \\
(0.356)\end{array}$ & $\begin{array}{c}-7.519 * * * \\
(0.260)\end{array}$ \\
\hline$p^{U P}(24 \mathrm{~h}$ lag $)$ & $\begin{array}{c}0.621 * * * \\
(0.041)\end{array}$ & $\begin{array}{c}0.746^{* * * *} \\
(0.040)\end{array}$ \\
\hline$p^{D N}(24 \mathrm{~h}$ lag $)$ & $\begin{array}{c}\text { 7.972*** } \\
(0.341)\end{array}$ & $\begin{array}{c}7.855^{* * *} \\
(0.305)\end{array}$ \\
\hline SIGN (24 h lag) & $\begin{array}{c}-130.200 * * * \\
(7.339)\end{array}$ & $\begin{array}{c}-129.728^{* * * *} \\
(6.094)\end{array}$ \\
\hline Constant & $\begin{array}{c}-88.780 \\
(0.000)\end{array}$ & $\begin{array}{c}410.763 * * * \\
(28.508)\end{array}$ \\
\hline Observations & 83,976 & 83,976 \\
\hline YMDH TFE & Yes & Yes \\
\hline Pooled OLS with Newey-West SE & $\mathrm{x}$ & \\
\hline Panel regression with fixed effects & & $\mathrm{x}$ \\
\hline
\end{tabular}

Standard errors in parentheses. ${ }^{* *} p<0.05,{ }^{*} p<0.1$.

*** $p<0.01$.
Table 15

Diagnostic tests on residuals.

\begin{tabular}{lr}
\hline Wooldridge test for autocorrelation in panel data & \\
$\mathrm{F}(1,1)=$ & 175.775 \\
Prob $>\mathrm{F}=$ & 0.0479 \\
Wald test for heteroskedasticity & \\
chi $2(2)=$ & 723.62 \\
Prob $>$ chi $2=$ & 0 \\
\hline
\end{tabular}

and intermittent renewable generation resources) who are not yet allowed to participate in Balancing Markets and, therefore, excluded from the provision of balancing resources and related potential profits.

These conflicting requirements might be reconciled with the opening of Balancing Markets to demand-side and renewable resources (an ongoing process at the European level) and the concomitant adoption of a dual pricing scheme, whereby BRPs are unmistakably given incentives to define their energy programs diligently and prudently. In the meantime, the normative framework should clarify that, although the economic incentives are present, the core responsibility of a BRP lays in minimizing its individual imbalance. Similarly, BRPs should be aware that responding to market signals is a strategy which, although expected from an economic agent, also needs to be exercised within the scope and boundaries of the normative framework.

The implications of this study are somehow in contrast with a European framework that gives preference to single pricing schemes (EU, 2017). For this and other reasons, further research directions are worth investigation. While this paper studied the differential impact of the two imbalance pricing schemes in terms of programming accuracy, an interesting extension would look into welfare-related issues, such as their impact on BRPs' and TSOs' balancing costs. Also, in the same direction, it would be interesting to explore the welfare effect of shifting a potentially significant volume of energy transactions from more liquid and competitive Day-Ahead markets to more concentrated and volatile Balancing Markets. Finally, market agents and regulator alike would benefit from a better understanding of whether a line should be drawn (and where), between responding to market signals and abusive behavior. All this would contribute to the design of efficient, secure and less carbon intensive power markets.

Table 16

Impact of the regulatory reform on the demand-side imbalance in the Italian macro-zone South - Generalized Least Squares Panel regression.

\begin{tabular}{lcccc}
\hline & $(1)$ & $(2)$ & $(3)$ & $(4)$ \\
\hline TREATED & $275.448^{* * *}$ & $274.833^{* * *}$ & $273.832^{* * *}$ & $273.649^{* * *}$ \\
& $(42.895)$ & $(42.076)$ & $(39.007)$ & $(38.464)$ \\
REG_CHANGE & $-155.840^{* *}$ & $-142.227^{* *}$ & $-139.968^{* *}$ & $-142.705^{* *}$ \\
& $(61.534)$ & $(62.433)$ & $(57.285)$ & $(56.998)$ \\
DIFF & $-303.874^{* * *}$ & $-302.752^{* * *}$ & $-299.723^{* * *}$ & $-299.237^{* * *}$ \\
& $(72.485)$ & $(71.084)$ & $(65.953)$ & $(65.047)$ \\
$p^{\text {DA }}$ (24 h lag) & & $-1.647^{* * *}$ & $-1.871^{* * *}$ & $-1.875^{* * *}$ \\
& & $(0.320)$ & $(0.324)$ & $(0.324)$ \\
$p^{\text {UP }}$ (24 h lag) & & & 0.005 & 0.003 \\
& & & $(0.025)$ & $(0.025)$ \\
$p^{\text {DN }}$ (24 h lag) & & & $1.045^{* * *}$ & $1.031^{* * *}$ \\
& & & $(0.219)$ & $(0.220)$ \\
SIGN (24 h lag) & & & & $-9.435^{* *}$ \\
& & & & $(4.207)$ \\
Constant & $209.228^{*}$ & $280.831^{* *}$ & $263.038^{* *}$ & $269.927^{* * *}$ \\
& $(11.033)$ & $(113.049)$ & $(104.235)$ & $(103.704)$ \\
Observations & 42,036 & 41,988 & 41,988 & 41,988 \\
YMDH TFE & Yes & Yes & Yes & Yes \\
\hline
\end{tabular}

Standard errors in parentheses.

*** $p<0.01$.

$* * p<0.05$

$* p<0.1$. 


\section{Appendix A. Supplementary data}

Supplementary data to this article can be found online at https://doi. $\operatorname{org} / 10.1016 / j$.eneco.2019.05.008.

\section{References}

Akaike, H., 1974. A new look at the statistical model identification. IEEE Trans. Autom. Control 19 (6), 716-723.

ARERA, 2006. Condizioni per l'erogazione del pubblico servizio di dispacciamento dell'energia elettrica sul territorio nazionale e per l'approvvigionamento delle relative risorse su base di merito economico, ai sensi degli articoli 3 e 5 del decreto legislativo 16 marzo 1999, n. 79. Resolution 111/06. Available (in Italian) from. www.areara it

ARERA, 2016a. Mercato dell'energia elettrica: revisione della disciplina degli sbilanciamenti effettivi - interventi prioritari. Consultation Document 316/2016/R/EEL Available (in Italian) from:. www.areara.it.

ARERA (2016b). Avvio di procedimento per l'adozione tempestiva di misure prescrittive e la valutazione di potenziali abusi nel mercato all'ingrosso dell'energia elettrica, ai sensi del regolamento (UE) 1227/2011 - REMIT. Resolution 342/16/E/EEL. Available (in Italian) from: www.areara.it.

ARERA (2016c). Interventi prioritari in materia di valorizzazione degli sbilanciamenti effettivi nell'ambito del dispacciamento elettrico. Resolution 444/2016/R/EEL. Available (in Italian) from: www.areara.it.

Boogert, A., Dupont, D., 2005. On the effectiveness of the anti-gaming policy between the dayahead and real-time electricity markets in The Netherlands. Energy Econ. 27 (5), 752-770.

Dickey, D.A., Fuller, W.A., 1979. Distribution of the estimators for autoregressive time series with a unit root. J. Am. Stat. Assoc. 74 (366a), 427-431.

EU, 2016. Proposal for a Directive of the European Parliament and of the Council on Common Rules for the Internal Market in Electricity (Recast). COM/2016/0864 Final/2 - 2016/0380 (COD) (Available from: eur-lex.europa.eu).

EU, 2017. Commission Regulation (EU) 2017/2195 of 23 November 2017 Establishing a Guideline on Electricity Balancing (Available from: eur-lex.europa.eu).
Haring, T.W., Kirschen, D.S., Andersson, G., 2015. Incentive compatible imbalance settlement. IEEE Trans. Power Syst. 30 (6), 3338-3346.

Hodge, B.M., Lew, D., Milligan, M., 2013, April. Short-term load forecast error distributions and implications for renewable integration studies. 2013 IEEE Green Technologies Conference (GreenTech). IEEE, pp. 435-442.

Hu, J., Harmsen, R., Crijns-Graus, W., Worrell, E., van den Broek, M., 2018. Identifying barriers to large-scale integration of variable renewable electricity into the electricity market: a literature review of market design. Renew. Sust. Energ. Rev. 81, 2181-2195.

Juselius, K., 2006. The Cointegrated VAR Model: Methodology and Applications. OUP, Oxford.

Just, S., Weber, C., 2015. Strategic behavior in the German balancing energy mechanism: incentives, evidence, costs and solutions. J. Regul. Econ. 48 (2), 218-243.

Möller, C., Rachev, S.T., Fabozzi, F.J., 2011. Balancing energy strategies in electricity portfolio management. Energy Econ. 33 (1), 2-11.

Newey, W.K., West, K.D., 1987. A simple, positive semi-definite, heteroskedasticity and autocorrelation consistent covariance matrix. Econometrica 55 (3), 703-708.

Perez-Arriaga, I.J., Batlle, C., 2012. Impacts of intermittent renewables on electricity generation system operation. Econ. Energy Environ. Policy 1 (2), 3-18.

Phillips, P.C., Perron, P., 1988. Testing for a unit root in time series regression. Biometrika 75 (2), 335-346.

Scherer, M., Haubensak, O., Staake, T., 2015. Assessing distorted trading incentives of balance responsible parties based on the example of the Swiss power system. Energy Policy $86,792-801$.

Schwarz, G., 1978. Estimating the dimension of a model. Ann. Stat. 6 (2), 461-464.

Terna, 2005. Grid Code. Available from: terna.it.

Vandezande, L., Meeus, L., Belmans, R., Saguan, M., Glachant, J.M., 2010. Well-functioning balancing markets: a prerequisite for wind power integration. Energy Policy 38 (7) 3146-3154.

van der Veen, R.A., Abbasy, A., Hakvoort, R.A., 2012. Agent-based analysis of the impact of the imbalance pricing mechanism on market behavior in electricity balancing markets. Energy Econ. 34 (4), 874-881.

Wawer, T., 2007. Incentives for gaming the German real-time electricity pricing mechanism. Proceeding of the 30th IAEE International Conference, Wellington. 